\title{
CORRIGENDUM
}

\section{Corrigendum to "The Deep Electrical Structure of Southern Taiwan and Its Tectonic Implications"}

\author{
[Terr. Atmos. Ocean. Sci., Vol. 21, No. 6, 879-895, December 2010] \\ Chih-Wen Chiang ${ }^{1}$, Chien-Chih Chen ${ }^{1, *}$, Martyn Unsworth ${ }^{2}$, Edward Bertrand ${ }^{2}$, \\ Chow-Son Chen ${ }^{1}$, Thong Duy Kieu ${ }^{1,3}$, and Han-Lun Hsu ${ }^{1}$ \\ ${ }^{1}$ Institute of Geophysics, National Central University, Jhongli, Taiwan, ROC \\ ${ }^{2}$ Department of Physics, University of Alberta, Edmonton, Alberta, Canada \\ ${ }^{3}$ Department of Geophysics, Hanoi University of Mining and Geology, Hanoi, Vietnam
}

Received 26 September 2009, accepted 25 February 2010

The above paper was originally printed with minor errors. The corrected details are printed below.

(1) The time period in each panel in Fig. 5 (see page 886) should be "Period" instead of "Priod."
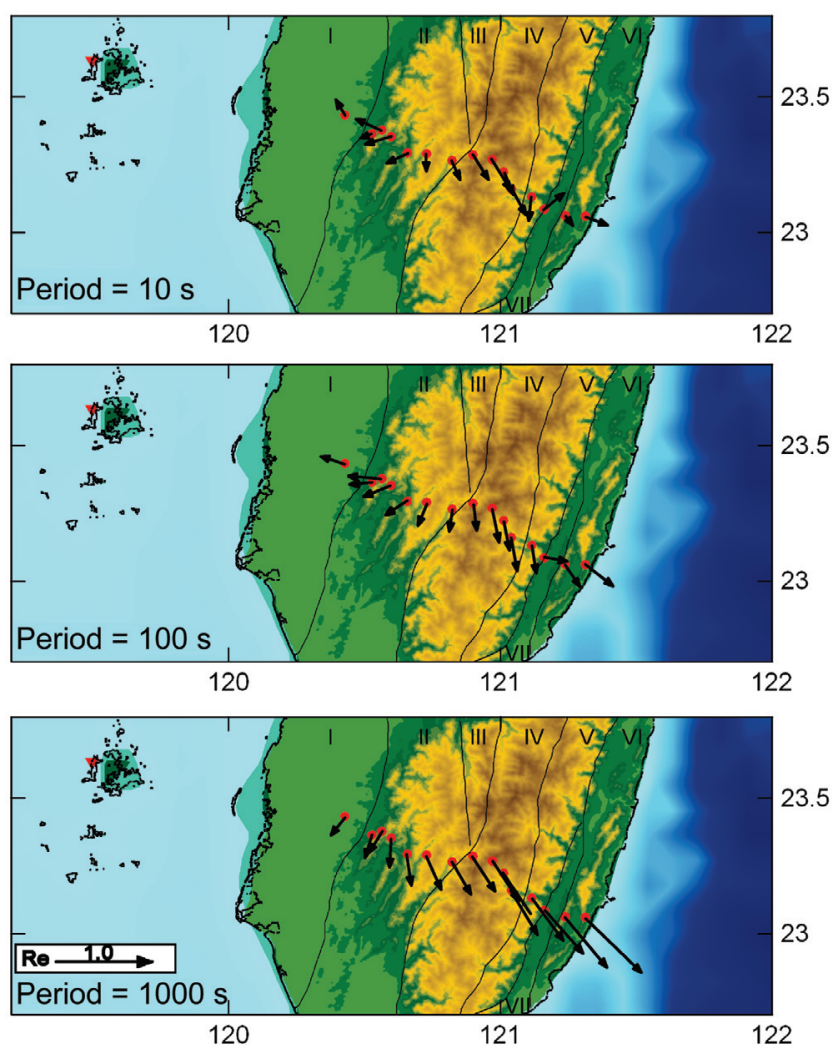

(3) Line 7 of right column on page 892, the last compound should be "early stage collision" instead of "post-collision."
(2) The y-axes in panels (c) and (d) in Fig. 9 (see page 889) should be "Depth (km)" instead of "Depth (m)."
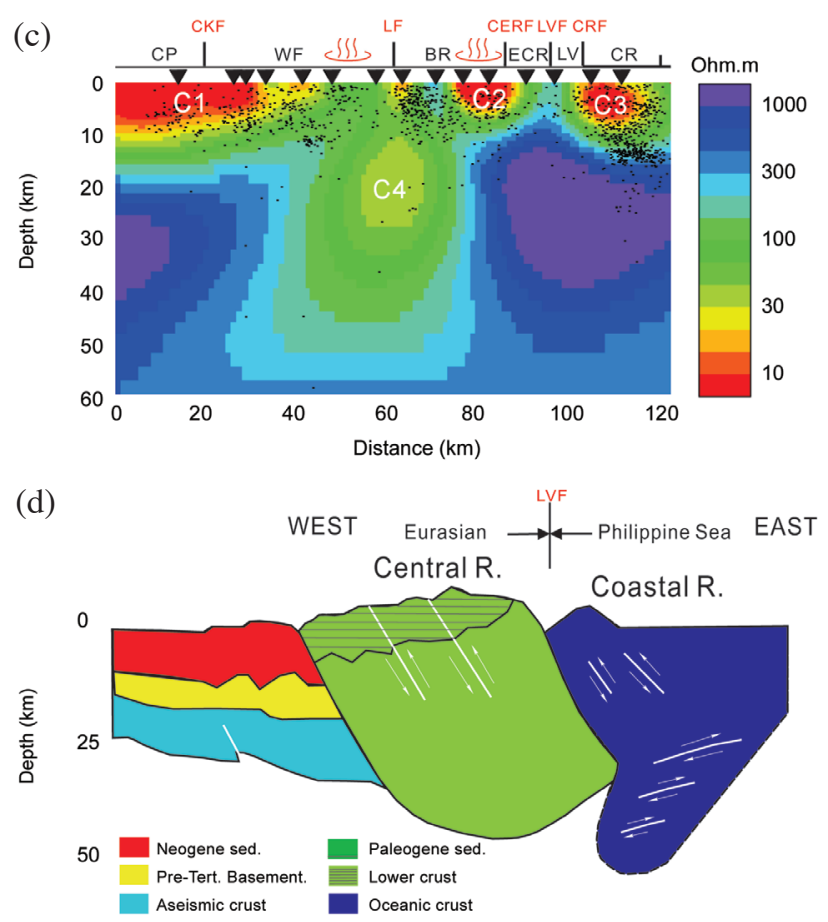

\footnotetext{
* Corresponding author

E-mail: chencc@earth.ncu.edu.tw
} 